\title{
Methylmercury exposure and mortality in southern Japan: a close look at causes of death
}

\author{
HIDEHIKO TAMASHIRO, ${ }^{1}{ }^{*}$ MIKIO ARAKAKI, ${ }^{1}$ MAKOTO FUTATSUKA, ${ }^{2}$ \\ AND EUN SUL LEE ${ }^{3}$ \\ From the Department of Epidemiology, ${ }^{1}$ National Institute for Minamata Disease, 4058-18 Hama, Minamata \\ City, Kumamoto, 867 Japan; Department of Public Health, ${ }^{2}$ Kumamoto University Medical School, Japan; and \\ School of Public Health, ${ }^{3}$ University of Texas Health Science Center at Houston, PO Box 20186, Houston, Texas \\ 77225, USA
}

SUMMARY This study examines mortality patterns by cause of death to investigate the effect of exposure to methylmercury in a small area of Minamata City (Kumamoto Prefecture, Japan), which has the highest concentration of patients with Minamata disease. Standardised mortality ratios (SMRs) are computed by cause of death for the study area, using the age specific rates of the entire city as a standard. The SMRs for liver cancer and chronic liver disease in the study area are significantly higher than unity and are consistent with the mortality patterns of registered Minamata disease patients. While an excess mortality is observed for cerebral haemorrhage, mortality from cerebral infarction and other cerebrovascular diseases is considerably lower in the study area. The multiple risk factors of liver related diseases and a possible explanation for the cerebrovascular mortality patterns are discussed to suggest further investigation.

Minamata disease was first reported in 1956, and it is now established that this disease is caused by the ingestion of fish and shellfish that are contaminated with methylmercury. The source of this substance was traced to a chemical plant in Minamata City, Kumamoto Prefecture, Japan (Chisso factory in the figure). At the end of 1983 there were 1612 confirmed cases in this prefecture, including 527 deaths. Numerous studies have been conducted using these confirmed cases, but few community based studies have been initiated. This study examines the total mortality patterns by cause of death in a small area of Minamata City, where most of the confirmed cases originated.

These confirmed cases, which have been registered, may not represent the total population since they were self reported and had met the required medical and epidemiological criteria to be registered as such. Deaths from liver cancer, chronic liver disease, and liver cirrhosis are reported to be significantly more frequent among registered Minamata disease patients than among the general population of Minamata City, and deaths from hypertensive diseases are relatively less frequent. ${ }^{1}$ Because of the suspected underreporting of cases one question presents itself:

*Present address: Epidemiology and Management Support Services, Division of Communicable Diseases, World Health Organisation, 1211 Geneva 27 , Switzerland.
Are the mortality patterns observed among confirmed cases consistent with the mortality experience of the total community exposed to this agent? This study attempts to find answers by analysing the complete mortality data of the designated methylmercury exposed area by cause of death.

\section{Materials and methods}

The study area consists of two small administrative subunits (Fukuro and Tsukinoura) in the coastal section of Minamata City (figure). About $70 \%$ of the total number of patients with confirmed Minamata disease in Kumamoto Prefecture have resided in the study area. Surveys conducted in 1960-2 showed that the average mercury concentration in human hair was high among inhabitants of the study area; ${ }^{2}$ and the cumulative prevalence rate of Minamata disease is much higher in the study area than in surrounding areas. $^{3}$ The inhabitants of this area are mainly fishermen and their families. Migration patterns of the areas affected with Minamata disease have been investigated. ${ }^{34}$ Migrants were mostly young adults, and more people moved out than moved in over the years. Immigrants were mostly former residents who returned to the study area. It is therefore reasonable to 


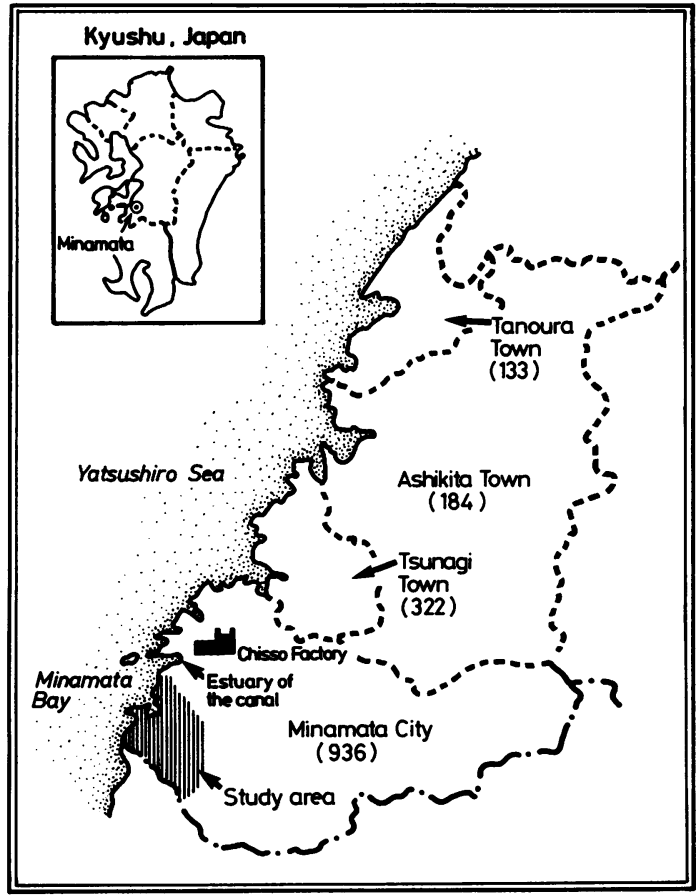

Study area and distribution of Minamata disease patients (numbers in parentheses denote number of registered cases as of June 1984).

assume that most of the present residents of the study area have been exposed to the agent.

The data used for the study were abstracted from the population registry of Minamata City, which contains all the demographic and vital information of its inhabitants. ${ }^{4}$ Death certificates for the period 1970-81 were retrieved from the District Legal Affairs Bureau and coded by place of residence. Causes of death were coded according to the International Classification of Diseases and injuries (ICD), and the selection of underlying causes of death was based on the WHO rule. ${ }^{5}$ Because the 8 th revision of ICD had been used for $1970-8$, deaths during those years were recorded according to the 9th revision, to make the data compatible with the 1979-81 classification criteria.

Mortality data before 1970 are not available from the registry, and the corresponding death certificates cannot be retrieved. But because more than $90 \%$ of deaths from Minamata disease were recorded after $1970,{ }^{3}$ the effect, if any, of methylmercury exposure on the mortality of the general population should be manifested after that date. A preliminary analysis did indicate that mortality rates during $1953-69$ in the area exposed to methylmercury were not significantly different from those in the whole of Minamata City. ${ }^{6}$
Population data taken from the 1975 population census show 3887 inhabitants in the study area, which accounted for $10.6 \%$ of Minamata City residents (table 1). There were 216 male and 196 female deaths from 1970 to 1981 , and except for one female death the cause of death was ascertained in all cases.

The expected number of deaths and the standardised mortality ratio (SMR) for the study area were computed using as its standard the age specific death rates (five-year intervals) of Minamata City by cause of death for 1972-8. A 95\% confidence interval was calculated for each SMR, assuming that the number of deaths follows a Poisson distribution when the expected number of deaths was less than 30 , or normal distribution when the number of deaths was 30 or more.

\section{Results}

Table 2 shows SMRs by sex and cause of death and their $95 \%$ confidence intervals in the study area during 1970-81. The SMR for all causes of death is 104.6. This indicates that the study area has about $5 \%$ higher mortality than the city, but the difference is statistically not significant. The overall SMR is 97.7 for males and 111.4 for females. Though neither SMR is shown to be significantly different, the study area's mortality rate is slightly lower for males and higher for females than the mortality rate of the total population of Minamata City.

Although the data cover a 12-year period from 1970 to 1981 , death totals are still quite small for some causes of death. Therefore the cause-specific SMRs should be interpreted with caution using confidence intervals. Fifteen major causes, with subcategories for six of them, are shown in table 2.

For males and females combined, the cause-specific SMRs, which are two times more than unity, include cancer of the oesophagus, cancer of the liver, cancer of the breast, chronic liver disease and cirrhosis, and senility without mention of psychosis. Among these, liver cancer, chronic liver disease and cirrhosis, and

Table 1 Population and number of deaths in a methylmercury-exposed area

\begin{tabular}{|c|c|c|c|c|}
\hline & \multicolumn{2}{|c|}{ Fukuro-Tsukinoura Area } & \multicolumn{2}{|c|}{ Minamata City } \\
\hline & Population* & $\begin{array}{l}\text { No. of } \\
\text { deathst }\end{array}$ & Population* & $\begin{array}{l}\text { No. of } \\
\text { deathst }\end{array}$ \\
\hline $\begin{array}{l}\text { Total } \\
\text { Male } \\
\text { Female }\end{array}$ & $\begin{array}{ll}3887 \\
1869 \\
2018\end{array}$ & $\begin{array}{l}416 \\
216 \\
196\end{array}$ & $\begin{array}{l}36782 \\
16970 \\
19812\end{array}$ & $\begin{array}{l}2325 \\
1233 \\
1092\end{array}$ \\
\hline
\end{tabular}

* 1975 census population

$+\quad 1970-81$

† 1972-8 
Table 2 Sex-and cause-specific standardised mortality ratio (SMR) in a methylmercury-exposed area, 1970-81

\begin{tabular}{|c|c|c|c|c|c|c|c|c|c|c|}
\hline & & \multicolumn{3}{|l|}{ Total } & \multicolumn{3}{|l|}{ Males } & \multicolumn{3}{|l|}{ Females } \\
\hline \multicolumn{2}{|c|}{ Cause of death } & $\begin{array}{l}\text { No. of } \\
\text { deaths }\end{array}$ & $S M R$ & $(95 \% \mathrm{CI})$ & $\begin{array}{l}\text { No. of } \\
\text { deaths }\end{array}$ & $S M R$ & $(95 \% C I)$ & $\begin{array}{l}\text { No. of } \\
\text { deaths }\end{array}$ & $S M R$ & $(95 \% C I)$ \\
\hline \multicolumn{2}{|c|}{ All causes } & $412 *$ & $104 \cdot 6$ & $(94 \cdot 9-115 \cdot 2)$ & 216 & $97 \cdot 7$ & $(85.5-111 \cdot 6)$ & $196^{*}$ & $111 \cdot 3$ & $(96 \cdot 8-128 \cdot 1)$ \\
\hline 1 & Gastroenteritis $(008,009,535,555,556,558,562)$ & 5 & $101 \cdot 0$ & $(32.8-235-6)$ & 1 & 56.7 & $(1.4-316.0)$ & 4 & $127 \cdot 6$ & $(34 \cdot 8-326 \cdot 7)$ \\
\hline 2 & Tuberculosis $(010-018)$ & 2 & $27 \cdot 6 \pm$ & $(3.3-99.8)$ & 2 & 41.9 & $(5 \cdot 1-151 \cdot 3)$ & 0 & - & $(-)$ \\
\hline & Cancers at all sites $(140-208)$ & 84 & $118 \cdot 2$ & $(95 \cdot 5-146 \cdot 3)$ & 52 & $122 \cdot 7$ & $(93.6-160.9)$ & 32 & $107 \cdot 3$ & $(76 \cdot 0-151 \cdot 5)$ \\
\hline & Oesophagus (150) & 5 & $204 \cdot 9$ & $(66 \cdot 5-478 \cdot 3)$ & 4 & $244 \cdot 7$ & $(66.7-626.5)$ & 1 & $119 \cdot 6$ & $(3.0-666 \cdot 1)$ \\
\hline & Stomach (151) & 14 & $77 \cdot 1$ & $(42 \cdot 1-129 \cdot 3)$ & 8 & 69.0 & $(29.8-136.0)$ & 6 & $88 \cdot 3$ & $(32 \cdot 4-192 \cdot 2)$ \\
\hline & Liver (155) & 15 & $207 \cdot 3 t$ & $(116.0-341.9)$ & 13 & $250 \cdot 5 t$ & $(133.4-428.4)$ & 2 & $92 \cdot 3$ & $(11 \cdot 2-333.4)$ \\
\hline & Pancreas (157) & 3 & $98 \cdot 7$ & $(20 \cdot 3-288 \cdot 3)$ & 2 & $142 \cdot 5$ & $(17 \cdot 3-514 \cdot 6)$ & 1 & 60.8 & $(1.5-338.5)$ \\
\hline & Trachea-bronchus-lung (162) & 12 & 151.9 & $(78 \cdot 5-265 \cdot 2)$ & 12 & $165 \cdot 8$ & $(85 \cdot 7-289 \cdot 6)$ & 0 & - & $(-)$ \\
\hline & Breast $(174-175)$ & 3 & $263 \cdot 7$ & $(54.4-770.8)$ & 0 & - & $(-)$ & 3 & $265 \cdot 7$ & $(54 \cdot 8-776.6)$ \\
\hline & Uterus $(179-182)$ & 4 & $89 \cdot 2$ & $(24 \cdot 3-228 \cdot 4)$ & 0 & - & $(-)$ & 4 & $88 \cdot 8$ & $(24 \cdot 2-227 \cdot 2)$ \\
\hline & Leukaemia (204-208) & 4 & 181.9 & $(49 \cdot 5-465 \cdot 6)$ & 2 & $193 \cdot 3$ & $(23.4-698 \cdot 2)$ & 2 & $174 \cdot 7$ & $(21 \cdot 2-631 \cdot 1)$ \\
\hline & Other cancers & 24 & $98 \cdot 1$ & $(62.9-146.0)$ & 11 & $77 \cdot 0$ & $(38.4-137.8)$ & 13 & $122 \cdot 8$ & $(65.4-209.9)$ \\
\hline 4 & Diabetes mellitus (250) & 2 & $36 \cdot 3$ & $(4 \cdot 4-131 \cdot 3)$ & 1 & $49 \cdot 1$ & $(1 \cdot 2-273 \cdot 3)$ & 1 & $29 \cdot 5$ & $(0.7-164 \cdot 1)$ \\
\hline 5 & Noninflammatory disease of CNS $(330-349)$ & 0 & - & $(-)$ & 0 & - & $(-)$ & 0 & - & $(-)$ \\
\hline \multirow[t]{4}{*}{6} & Disease of heart $(393-398,410-429)$ & 41 & $68.4 !$ & $(50.4-92.9)$ & 18 & $57 \cdot 3 \pm$ & $(34.0-90.6)$ & 23 & 79.6 & $(50 \cdot 5-119 \cdot 5)$ \\
\hline & Ischaemic heart disease (410-414) & 14 & $49 \cdot 2 \pm$ & $(26.9-82 \cdot 5)$ & 7 & $45 \cdot 5 t$ & $(18.3-93.9)$ & 7 & $52 \cdot 7$ & $(21 \cdot 2-108 \cdot 6)$ \\
\hline & Chronic rheumatic heart disease \& disease of & 6 & 100.6 & $(36.9-219 \cdot 1)$ & 2 & $122 \cdot 3$ & $(14.8-441.6)$ & 4 & $94 \cdot 0$ & $(25 \cdot 6-240 \cdot 7)$ \\
\hline & Other heart disease & 21 & $82 \cdot 4$ & $(51 \cdot 0-125 \cdot 9)$ & 9 & 62.6 & $(28.6-118.8)$ & 12 & $105 \cdot 7$ & $(54 \cdot 6-184 \cdot 6)$ \\
\hline \multirow[t]{3}{*}{7} & Hypertensive disease $(401-405)$ & 14 & $60 \cdot 9$ & $(33 \cdot 3-102 \cdot 2)$ & 6 & $48 \cdot 2$ & $(17 \cdot 7-104.9)$ & 8 & $74 \cdot 5$ & $(32 \cdot 1-146 \cdot 7)$ \\
\hline & Hypertensive heart disease $(402-404)$ & 13 & $68 \cdot 2$ & $(36 \cdot 3-116 \cdot 6)$ & 5 & 46.0 & $(14.9-107.3)$ & 8 & $95 \cdot 4$ & $(41 \cdot 2-188 \cdot 0)$ \\
\hline & Other hypertensive disease & 1 & $25 \cdot 5$ & $(0.6-142.0)$ & 1 & 63.7 & $(1.6-354.6)$ & 0 & - & $(-)$ \\
\hline \multirow[t]{4}{*}{8} & Cerebrovascular disease $(430-438)$ & 65 & 93.8 & $(73.6-119.5)$ & 32 & $89 \cdot 2$ & $(63.2-126 \cdot 0)$ & 33 & $98 \cdot 0$ & $(69 \cdot 8-137 \cdot 6)$ \\
\hline & Cerebral haemorrhage $(431-432)$ & 44 & $166 \cdot 5 t$ & $(124 \cdot 0-223 \cdot 5)$ & 22 & $151 \cdot 3$ & $(94 \cdot 8-229 \cdot 1)$ & 22 & $181.9 \dagger$ & $(114 \cdot 0-275 \cdot 3)$ \\
\hline & Cerebral infarction $(433-434)$ & 3 & $19 \cdot 6 \pm$ & $(4 \cdot 0-57 \cdot 3)$ & 1 & $13.9 \pm$ & $(0.4 \quad 77.6)$ & 2 & $24 \cdot 7 \ddagger$ & $(3.0-89.4)$ \\
\hline & Other CVD & 18 & $65 \cdot 3$ & $(38 \cdot 7-103 \cdot 1)$ & 9 & 65.6 & $(29 \cdot 1-120 \cdot 6)$ & 9 & $66 \cdot 7$ & $(30.5-126 \cdot 7)$ \\
\hline \multirow[t]{3}{*}{9} & Pneumonia-Bronchitis $(466 \cdot 0,480-486,490,491)$ & 15 & $75 \cdot 4$ & $(42 \cdot 2-124 \cdot 4)$ & 4 & $36 \cdot 7 \ddagger$ & $(10.0-93.9)$ & 11 & $120 \cdot 8$ & $(60 \cdot 3-216 \cdot 1)$ \\
\hline & Pneumonia (480-486) & 12 & $69 \cdot 5$ & $(35 \cdot 9-121 \cdot 3)$ & 4 & $42 \cdot 1$ & $(11 \cdot 5-107 \cdot 7)$ & 8 & $101 \cdot 6$ & $(43.9-200 \cdot 3)$ \\
\hline & Bronchitis & 3 & $114 \cdot 6$ & $(23 \cdot 6-335 \cdot 0)$ & 0 & - & $(-)$ & 3 & $242 \cdot 4$ & $(50 \cdot 0-708 \cdot 5)$ \\
\hline 10 & Gastric, duodenal ulcer (531-533) & 6 & $71 \cdot 6$ & $(26 \cdot 3-155 \cdot 9)$ & 4 & $91 \cdot 6$ & $(25 \cdot 0-234 \cdot 5)$ & 2 & $49 \cdot 2$ & $(6.0-177.8)$ \\
\hline & Liver disease $(570-573)$ & 28 & $200 \cdot 0 t$ & $(133 \cdot 0-289 \cdot 1)$ & 20 & $294 \cdot 1 \dagger$ & $(179.6-454.2)$ & 8 & 114.5 & $(49 \cdot 4-225 \cdot 6)$ \\
\hline & Chronic liver disease \& cirrhosis (571) & 26 & $216 \cdot 0 t$ & $(141 \cdot 1-316 \cdot 5)$ & 18 & $294 \cdot 3+$ & $(174.4-465.0)$ & 8 & $139 \cdot 6$ & $(60.3-275 \cdot 0)$ \\
\hline & Other liver disease & 2 & 101.9 & $(12 \cdot 3-368 \cdot 3)$ & 2 & $292 \cdot 5$ & ( $35.4-1056 \cdot 6)$ & $\mathbf{0}$ & - & $(-)$ \\
\hline 12 & Nephritis, nephrosis, nephrotic syndrome $(580-589)$ & 9 & 155.0 & $(70 \cdot 9-294 \cdot 2)$ & 3 & $80 \cdot 8$ & $(16 \cdot 7-236 \cdot 1)$ & 6 & $276 \cdot 5 t$ & $(101 \cdot 5-601 \cdot 9)$ \\
\hline 13 & Senility (797) & 34 & $233.6 t$ & $(167 \cdot 2-326 \cdot 4)$ & 15 & $244 \cdot 1 \dagger$ & $(136 \cdot 6-402.6)$ & 19 & $227 \cdot 5 t$ & $(137 \cdot 0-355 \cdot 2)$ \\
\hline 14 & Accident-poisoning-suicide (E104-E115) & 48 & $148 \cdot 3 \dagger$ & $(111 \cdot 9-196 \cdot 6)$ & 34 & $135 \cdot 4$ & $(96.9-189 \cdot 1)$ & 14 & $170 \cdot 4$ & $(93 \cdot 2-285 \cdot 9)$ \\
\hline 15 & All other causes & 58 & $104 \cdot 5$ & $(80 \cdot 9-135 \cdot 1)$ & 24 & 74.9 & $(48 \cdot 0-111 \cdot 3)$ & 34 & $142 \cdot 3 t$ & $(101 \cdot 8-198 \cdot 8)$ \\
\hline
\end{tabular}

* Includes one unknown cause of death.

$\uparrow$ Significantly higher.

$\ddagger$ Significantly lower.

senility are significantly higher at the $5 \%$ level. Though somewhat lower, the SMRs for cerebral haemorrhage and accident-poisoning-suicide (including Minamata disease) are also significantly higher. On the other hand, significantly lower ratios are shown for tuberculosis, ischaemic heart disease, and cerebral infarction.

Significantly raised SMRs for males are shown for liver cancer, chronic liver disease and cirrhosis, and senility, while SMRs for ischaemic heart disease, cerebral infarction, and bronchopneumonia are significantly lower in the study area. For females, SMRs are significantly higher for cerebral haemorrhage, nephritic diseases, senility, and the all other causes category; the female SMR for cerebral infarction is significantly lower.

\section{Discussion}

The findings demonstrate that mortality rates in the area exposed to methylmercury are substantially higher for liver cancer, chronic liver disease and cirrhosis, cerebral haemorrhage, and senility, as well as accidents and poisoning. They are significantly lower for ischaemic heart disease, cerebral infarction, and tuberculosis. These results are generally compatible with the mortality pattern observed among patients with registered Minamata disease. ${ }^{1}$ Several points are worth discussing.

Firstly, the fact that the SMRs for males and females are not significantly raised for accident-poisoning-suicide (this category includes Minamata disease) may be due to the low proportion 
$(14 \%)$ of Minamata disease in this category, based on underlying causes of death reported on the death certificate. ${ }^{7}$ If we could examine Minamata disease itself as a contributory cause of death, more convincing evidence could probably be shown.

Secondly, the increased mortality from liver cancer and chronic liver disease observed in the study area is consistent with the mortality patterns shown among the registered Minamata disease patients. This relation between exposure to methylmercury and liver disease should be interpreted in conjunction with other aetiological agents of liver disease. A preliminary report indicates that $\mathrm{Hbs}-\mathrm{Ag}$ and $\mathrm{Hbs}-\mathrm{Ab}$ are also more prevalent in this area where the inhabitants consume more alcohol than the average Japanese. ${ }^{8}$ It has been shown that ethanol enhances toxicity and mortality in mice and rats. ${ }^{9-11}$ Further epidemiological and toxicological studies are needed to investigate how alcohol and other factors can affect or modify the pathogenesis of methylmercury toxicity.

Finally, the excess mortality from cerebral haemorrhage shown in this study is in accord with the reported pathological changes in cerebral blood vessels in human and animal cases of organic mercury intoxication. ${ }^{12-14}$ The significance of this finding cannot be overemphasised. In the light of these neuropathological processes of organic mercury intoxication, public health officials have expressed much concern about the expected increase in cardiovascular disease in the methylmercury-exposed areas. Such an increase has not yet been observed among registered Minamata disease patients. ${ }^{7-15}$ Even in the present study, mortality from all cerebrovascular diseases is not significantly different from that in the whole city. In fact mortality from cerebral infarction is significantly lower, although the SMR is based on only three deaths. Mortality from ischaemic heart disease is significantly lower in the study area, which is not consistent with the suggested relation between mercury and cardiovascular disease ${ }^{16}$ or with the elevated systolic blood pressure in rats fed with mercury for a year. ${ }^{17}$

This perplexing finding prompts us to offer several plausible explanations. Firstly, there is a suggestion of delayed effects of methylmercury exposure, especially in cases of mild exposure, which would be manifested in subsequent development of cerebral blood vessel atherosclerosis associated with aging. ${ }^{14}$ For this we need a long-term follow up study of Minamata disease patients $^{12}$ as well as continuing epidemiological studies such as the present one. Another possible line of explanation can be sought in the suggestion that methylmercury exposure might have supressing effects on certain cardiovascular diseases. This can be further investigated by examining interacting effects of methylmercury exposure with other aetiological factors of cardiovascular diseases other than haemorrhage and also by conducting a comprehensive competing risk analysis of detailed causes of death. ${ }^{18}$ Still another line of inquiry must be made into possible anomalies in mortality data. In this part of Japan there may still be some problems with accuracy in reporting causes of death from particular circulatory diseases. We need to determine if these observations are due to reporting errors before looking into the physiological consequences of methylmercury poisoning or the competing risk hypothesis.

We are grateful to Ms M L Holliday for her skilled editing of this paper.

\section{References}

${ }^{1}$ Tamashiro H, Arakaki M, Akagi H, Futatsuka M, Higa $K$. Mortality and causes of death among Minamatao disease patients. Jpn J Publ Hlth (in Japanese with English summary) 1983, 30: 403-12.

2 Matsushima Y, Mizoguchi S, Doi S, Chiyo S. Surveys on mercury levels in human hair from the Minamata disease-affected areas. Annual Rep Kumamoto Perfec Inst Hyg (in Japanese) 1961, 1962, and 1963.

${ }^{3}$ Arakaki M, Tamashiro H, Futatsuka M. A demographic study in the epidemic area of Minamata disease (Part 1). Jpn J Human Ecol Hyg (in Japanese) 1984, 50 (Suppl.): 68-9.

${ }^{4}$ Tamashiro H, Arakaki M, Futatsuka M. A demographic study in the epidemic area of Minamata disease (Part 2). Jpn J Human Ecol Hyg (in Japanese) 1984, 50 (Suppl.): 70-1.

${ }^{5}$ World Health Organization. Manual of the international classification of diseases and injuries, Ninth revision. 1975, Geneva: World Health Organization.

${ }^{6}$ Tamashiro H, Arakaki M, Shibata Y, Suzuki T, Akagi H, Futatsuka M, Nomura S. A mortality study in the methylmercury-exposed area. Jpn J Publ Hlth (in Japanese with English summary) 1984, 31: 21-34.

${ }^{7}$ Tamashiro H, Akagi H, Arakaki M, Futatsuka M, Roht LH. Causes of death in Minamata disease: analysis of death certificates. Int Arch Occ Envir Hlth 1984, 54: $135-46$.

${ }^{8}$ Futatsuka $M$, Ueda $A$, Yasutake $R$, and Nomura $S$. Estimation of methylmercury intake in Minamata district. Kumamoto Med J 1982, 35: 23-33.

${ }^{9}$ Takahashi H, Shibuya H, Fukushima Y. A study of the factors influencing toxicity of methylmercury. Kumamoto Univ Med Sch Toxic Rep (in Japanese) 1978, 11: 15-6.

${ }^{10}$ Turner CJ, Bhatnagar MK, Yamashiro S. Ethanol potentiation of methylmercury toxicity: a preliminary report. J Toxic Envir Hlth 1981, 7: 665-8.

11 Tamashiro H, Arakaki M, Akagi H, Murao K, Hirayama $\mathrm{K}$. Factors influencing methylmercury toxicity in rats: effects of ethanol. Jpn $J$ Publ Hlth (in Japanese with English summary) 1985, 32: 397-401. 
${ }^{12}$ Shiraki $\mathbf{H}$. The necessity of long-term follow-up study on organic mercury intoxication from neuropathological viewpoint. Adv Neurol Sci (in Japanese) 1969, 13: 113-20.

${ }^{13}$ Shiraki H, Nagashima K. Essential neuropathology of alkylmercury intoxication in humans from the acute to the chronic stage with special reference to experimental whole body autoradiographic study using labeled mercury compounds. In: Roizin L, Shiraki H, Grcevic N (eds) Neurotoxicology. New York: Raven Press, 1977, 247-260.

${ }^{14}$ Shaw CM, Mottet NK, Luschei ES, Finocchio DV Cerebrovascular lesions in experimental methylmercurial encephalopathy. Neurotoxicol 1979, 1: 57-74.
${ }^{15}$ Tamashiro H, Arakaki M, Akagi H, Futatsuka M, Higa $\mathrm{K}$. Mortality and life-table in Minamata disease. Jpn J Publ Hlth (in Japanese with English summary) 1983, 30: 403-12.

${ }^{16}$ Shaper AG. Cardiovascular diseases and trace metals. Proc $R$ Soc Lond B, 1979, 205: 135-43.

${ }^{17}$ Perry HM, Erlanger M W. Metal-induced hypertension following chronic feeding of low doses of cadmium and mercury. J Lab Clin Med, 1974, 83: 541-7.

${ }^{18}$ Birnbaum ZW. On the mathematics of competing risks. Vital and Health Statistics: Series 2 , no 77,1979 , USDHEW Pub. (PHS) 79-1351, US Government Printing Office. 